1 Seasonal rainfall forecasting for the Yangtze River basin using statistical

\title{
and dynamical models
}

\author{
Shuni Qian a , Jie Chen a, b *, Xiangquan Li a, Chong-Yu Xu ${ }^{\text {a, c }}$, Shenglian Guo a , Hua Chen a, \\ Xushu $\mathrm{Wu}^{\mathrm{a}}$ \\ ${ }^{a}$ State Key Laboratory of Water Resources and Hydropower Engineering Science, Wuhan \\ University, Wuhan 430072, China \\ ${ }^{\mathrm{b}}$ Hubei Provincial Key Lab of Water System Science for Sponge City Construction, Wuhan \\ University, Wuhan, Hubei, China \\ ${ }^{\mathrm{c}}$ Department of Geosciences, University of Oslo, P.O, Box 1047 Blindern, 0316 Oslo, Norway \\ ${ }^{*}$ Corresponding author address: State Key Laboratory of Water Resources and Hydropower \\ Engineering Science, Wuhan University, Wuhan 430072, China \\ E-mail: jiechen@whu.edu.cn
}

\begin{abstract}
Summer monsoon rainfall forecasting in the Yangtze River basin is highly valuable for water resource management and for the control of floods and droughts. However, improving the accuracy of seasonal forecasting remains a challenge. In this study, a statistical model and four dynamical global circulation models (GCMs) are applied to conduct seasonal rainfall forecasts for the Yangtze River basin. The statistical forecasts are achieved by establishing a linear regression relationship between the sea surface temperature (SST) and rainfall. The dynamical forecasts are achieved by downscaling the rainfall predicted by the four GCMs at the monthly and seasonal scales. Historical data of monthly SST and GCM hindcasts from 1982-2010 are used to make the forecast. The results show that the SST-based statistical model generally outperforms the GCM simulations, with higher forecasting accuracy that extends to longer lead times of up to 12 months. The SST statistical model achieves a correlation coefficient up to 0.75 and the lowest mean relative error of $6 \%$. In contrast, the GCMs exhibit a sharply decreasing forecast accuracy with lead times longer than 1 month. Accordingly, the SST statistical model can provide reliable guidance for the seasonal rainfall forecasts in the Yangtze River basin, while the results of GCM simulations could serve as a reference for shorter lead times. Extensive scope exists for further improving the rainfall forecasting accuracy of GCM simulations.
\end{abstract}

Keywords: seasonal forecasting; teleconnections; sea surface temperature; statistical model; GCMs 


\section{Introduction}

Rainfall forecasts are an essential component of hydrological forecasting systems and widely used in understanding the hydrological response to climate change at local, regional and global scales. Water resource management and agricultural development also need rainfall forecasts for planning and dealing with flood and drought events. Seasonal rainfall forecasting, defined as the forecast of rainfall in the next few months, is of great importance to the survival and development of humanity as it is highly demanded in agriculture, water resource management, and the energy sectors (McGregor and Phillips, 2004; Wetterhall et al., 2015). For example, seasonal forecasts can provide a warning about the coming rainy season, which might reduce the impact of droughts and floods by increasing the level of preparedness. Understanding the variation of seasonal rainfall and providing a reliable forecast are significant in disaster preventions.

Generally, seasonal rainfall forecasting includes the following two types of models: a) Dynamical models, which are employed in climate simulations of physical processes that reveal interactions between ocean, atmosphere and land (Alessandri et al., 2011); and b) Statistical models that employ statistically demonstrable relationships between various predictors such as sea surface temperature and hydro-climate variables such as rainfall and streamflow (Badr et al., 2014). In terms of dynamical models, coupled atmosphere-ocean-land global circulations models (CGCMs) have been used widely for obtaining forecasts at multiple timescales, ranging from medium-term weather forecasting ( 1 or 2 weeks), monthly and seasonal predictions (1 to 12 months), to long-term climate predictions (Kim et al., 2012; Kumar, 2005; Wang et al., 2010; Yuan et al., 2013). The multiple time scale capability of GCMs is due to their predictability from different sources, such as initial conditions from the atmosphere and slow evolution of boundary conditions, like soil moisture and SST (Pattanaik et al., 2012). Scientific and technological progress over the past years has resulted in the development of GCMs with a steadily increasing sophistication. Several GCMs have been currently developed and adopted for conducting climate forecasts, such as the Climate Forecast System Version 2 (CFSv2) model developed at the U.S. National Centers for Environmental Prediction (Yuan et al., 2011) and the European Centre for Medium-Range Weather Forecast's Systems 4 model (Kim et al., 2012; Vitart, 2014). The North American Multimodel Ensemble (NMME) project has assessed the strengths and weaknesses of more than 10 GCMs (Givati et al., 2017; Kirtman et al., 2014). However, the application of GCMs for seasonal forecasts has demonstrated greater facility for predicting sea surface variables like SST than land surface variables like rainfall (Ding and Ke, 2013; Smith et al., 2012), although the land surface variables have a more direct impact on society than the sea surface variables. For example, GCMs have demonstrated significant forecasting accuracy for Pacific SSTs for a lead time of up to 14 months, while the forecasting of precipitation has demonstrated a pronounced decrease in accuracy for lead time longer than one month (Villarini and Serinaldi, 2011).

In addition to GCMs, statistical methods have demonstrated wide practical application for rainfall and streamflow forecasting. The statistical methods commonly used for seasonal forecasts involve autoregressive models (Wang et al., 2016), canonical correlation analysis (Ciancarelli et al., 2014; Wilks, 2008), discriminant analysis (Viana and Sansigolo, 2016) and linear regression (Chen and Georgakakos, 2015; Tippett and DelSole, 2013; Knaff and Landsea, 1997). Of these, linear regression models for rainfall forecasting are particularly simple and are usually built by 
establishing a linear relationship between large-scale predictors and precipitation. Many studies have employed SST as the main predictor to estimate statistical relationships, because deviations from average SST conditions, denoted as SST anomaly (SSTA), play an important role in reflecting the fluctuations of atmospheric circulation that relate to land surface variables like rainfall (Chen and Georgakakos, 2013; Sittichok et al., 2016).

Given the wide use of these dynamical and statistical models, the verification of their forecasting skills is necessary. A good weather forecast is usually identified as three types of goodness (Murphy 1993): Type 1 is the correspondence between the judgments and the forecasts of the forecasters (consistency). For forecasters, the forecasts must reflect the uncertainty of their judgments, then, the forecasts are more properly to be expressed in probabilistic or ensemble terms. Some common measures of the accuracy of probabilistic forecasts, such as the ranked probability score and the ensemble reliability are commonly used to evaluate high or low levels of consistency (Acharya et al., 2014; Chen and Georgakakos, 2013). Type 2 is the correspondence between the forecasts and observations (quality), prominent measures which focus on one or two aspects of forecast quality (accuracy and skill) are commonly used, such as the mean absolute error and the Pearson's correlation (Krishna Kumar, 2005; Wang et al., 2008). Type 3 indicates the benefits of the use of forecasts by decision makers (value). The value of the forecasts is not under the forecasters' control, thus, a forecaster can do no better than provides the best possible forecasts consistent with knowledge and judgements. Thus, previous researches mainly focus on the verification of the former two types of goodness.

Although both GCMs and statistical models show reasonable performance in the verification of seasonal forecasts, two questions still need to be discussed. Firstly, there are limited studies involved in comparing the difference of seasonal rainfall forecasting skill between dynamical models and statistical models over land. Even though GCMs show increasingly accurate forecasting skill in many climate variables, the skill of seasonal rainfall forecasting over land is not so satisfactory (Givati et al., 2017). It is necessary to evaluate the performance of GCMs in seasonal rainfall forecasts. In addition, the statistical and dynamical methods need to be compared to provide end-users with the information required for making decisions. Secondly, the accuracy of season rainfall forecasting is limited to a great extent by the adopted lead time. As such, evaluating the performance of different models with various lead times and extending the effective lead time of forecasting models is also essential for supporting the forecasting decisions.

Floods and droughts occur frequently in China during the summer time (Ding et al., 2008; Wu et al., 2017). This is particularly the case in the Yangtze River basin because the rainfall here exhibits strong intra- and interannual variabilities as a result of tropical air-sea interactions (Wang and Zhang, 2002). The Three Gorges Reservoir, which is the largest hydropower plant in the world, is located in the middle reach of the Yangtze River basin, and its electrical output is crucial for the management of energy sectors. Being the longest river in China, the Yangtze River possesses rich water resources that are greatly affected by variations in summer rainfall (Wu et al., 2018). For example, the 1998 flood in the Yangtze River basin resulted in extremely severe economic loss, thousands of deaths, and millions of homeless people (Jiang et al., 2008; Li et al., 2016). Moreover, in the context of climate change, rainfall extremes in the Yangtze River basin may be more frequent and severe in the future (Birkinshaw et al., 2017; Deng et al., 2013). However, in spite of the recent progress attained for climate forecasting, accurate monsoon rainfall forecasting for the Yangtze River basin monsoon rainfall remains a significant challenge. While numerous dynamical and statistical 
methods have been used to predict monsoon rainfall in this region, the forecasting accuracy obtained has thus far been undesirably low, particularly for long lead times (Alfiri et al., 2013; Lang et al., 2014; Li and Lin, 2015; Peng et al., 2014; Zhao et al., 2017). Nevertheless, the summer monsoon rainfall over the Yangtze River basin may be potentially predictable because a strong link between the EI Niño Southern Oscillation (ENSO) in the tropical region of the eastern Pacific and rainfall during the summer monsoon season (Cao et al., 2017; Hardiman et al., 2018; Hui et al, 2006). As a result, the accuracy of Yangtze River basin rainfall forecasting can be expected to improve using GCMs or SST statistical models owing to the relatively good performance of GCMs in strong ENSO periods and the stable correlation between SSTA and rainfall in the Yangtze River basin.

This article aims to: (1) investigate the underlying relationship between SSTA and summer monsoon rainfall in the Yangtze River basin; (2) compare the accuracy of monthly and seasonal monsoon rainfall forecasting employing simulations using four different GCMs and a SST statistical model over various lead times; and (3) determine the most precise rainfall forecasting method for the Yangtze River basin for given lead times to provide practical guidance to forecasters.

The article is organized as follows: Section 2 introduces the study area and data sources used in the study. Section 3 describes the SST statistical model and the derived rainfall forecasting method. Section 4 presents the forecasting results obtained using the four GCMs and the SST statistical model. Section 5 compares and discusses the forecasting accuracy of these two types of models. Section 6 provides a brief summary.

\section{Study area and data}

\subsection{Study area}

As shown in Fig. 1a, the study area covers the entire Yangtze River basin and the SSTA spatial domain. Considering the diversity of rainfall distribution, the Yangtze River basin is divided into an upper Yangtze River basin (UYRB) and a middle-lower Yangtze River basin (LYRB) using the Three Gorges Dam as a boundary. Rainfall in China is influenced by the ENSO (in the tropical region of Eastern Pacific Ocean) and modulated by the East Asian monsoon. Therefore, the area shown in Fig. $1 \mathrm{a}\left(65^{\circ} \mathrm{S}-65^{\circ} \mathrm{N}, 35^{\circ} \mathrm{E}-285^{\circ} \mathrm{E}\right)$ is adopted as the SSTA spatial domain.

\subsection{Data}

The long-term monthly rainfall data (Fig. 1b) presents a single high-rainfall period during JuneSeptember (JJAS), then the period of JJAS is selected as the target forecasting months. Observed monthly data in June, July, August, and September (JJAS) during the period of 1982-2010 are obtained from the China Meteorological Administration gauge-based gridded daily rainfall database (http://data.cma.cn/en/?r=data/detail\&dataCode=SURF_CLI_CHN_PRE_DAY_GRID_0.5) with a latitude and longitude resolution of $0.5^{\circ} \times 0.5^{\circ}$. Monthly rainfall data are aggregated from the daily data and then averaged over all grid cells in the UYRB and LYRB in this study. Kaplan SST data (Kaplan et al., 1998) obtained from NOAA/OAR/ESRL/PSD, Boulder, Colorado, USA (https://www.esrl.noaa.gov) are used for SST data in the present study. For SST statistical method, we employ the forecast lead time from 1 month to 12 months. The 1-month lead time means that the SST data in May are used to forecast June rainfall, and the average SST data in March- 
May(MAM) are used to forecast the average rainfall of June-August (JJA). The same definition is employed in other lead times and target forecasting months or season.

The NMME seasonal forecasting system provides global hindcasting data and real-time data obtained from more than $10 \mathrm{GCMs}$. In this paper, four GCMs (CFSv2, IRI-MOM3-AC, IRIMOM3-DC and CMC2) which over a common period of 1982 to 2010 are selected for comparison. The detailed information of these four GCMs is listed in Table 1. Since the form of ensemble mean is the simplest and most popular measure (Zhao et al., 2017; Dirmeyer and Harder, 2017), only ensemble mean monthly rainfall is used in this study. Considering the limited forecasting accuracy of GCMs for lead times longer than 1 month (Alessandri et al., 2011; Pokhrel et al., 2015), only 0month lead times and 1-month lead times are employed. Here, 0-month lead time indicates that, for example, data initiated in early June are used to forecast June rainfall, and for seasonal forecasting, data initiated in early June for the next three months of June to August (JJA) are used to forecast JJA mean rainfall, while 1-month lead times are the same as 0-month lead times, but the data are initiated in early May.

\section{Forecasting methods and parameters}

\subsection{Statistical forecasting model}

The dipole-based forecasting model is built by identifying the most significant SSTA regions that can best predict the rainfall time series according to the teleconnection patterns established between the most significant SSTA regions and rainfall. These most significant SSTA regions are identified using a systematic search procedure, denoted as a dipole search algorithm (Chen and Georgakakos, 2013), which defines the geographic location and the size of significant SSTA regions based on a significance threshold established according to the Gerrity Skill Score (GSS; Gerrity, 1992). The algorithm uses the difference between two SST pole regions as the predictor, which is defined as

$$
D_{\phi_{1}, \phi_{2}}(t)=\operatorname{Avg}\left[\phi_{1}\right] \pm \operatorname{Avg}\left[\phi_{2}\right]
$$

where $A v g$ represents the mean SST over a given pole region $\phi$. Therefore, the teleconnection between the two poles $\phi_{1}$ and $\phi_{2}$ represents an SST dipole. The GSS-based threshold is determined according to a hypothesis $H_{0}$ that the GSS of the SST dipole $\left(\mathrm{GSS}_{\mathrm{D}}\right)$ is equal to a random series $\left(\mathrm{GSS}_{\mathrm{R}}\right)$, and an alternative hypothesis indicating that $\mathrm{GSS}_{\mathrm{D}}$ is greater than $\mathrm{GSS}_{\mathrm{R}}$ as follows:

$$
\left\{\begin{array}{l}
H_{0}: G S S_{D}=G S S_{R}, \\
H_{1}: G S S_{D}>G S S_{R},
\end{array}\right.
$$

Here, $\mathrm{H}_{0}$ is rejected If $G S S_{D}>G S S_{R, \alpha}$ (where $\alpha$ is a significance level). The value of $G S S_{R, \alpha}$ can be calculated from the distribution of $G S S_{R}$ using the bootstrap method. Chen and Georgakakos (2013) found that $G S S_{R, \alpha}$ is determined only by the data size and $G S S_{R, \alpha=0.05}$ approaches a constant of about 0.25 when the data size reaches 30 . Therefore, the significant SST dipoles are determined based on the dipole search algorithm with GSS $=0.25$ as the significance threshold. The parameters used in the dipole search algorithm in the present study are summarized in Table 2. 
The significant SST dipoles are then used to establish linear regressions as

$$
Y^{i}=D^{i} \hat{\beta}^{i}, \quad i=1,2, \ldots, \xi ;
$$

where $Y^{i}$ denote the historical monthly or seasonal rainfall values, $D^{i}$ are the $D_{\emptyset_{1}, \emptyset_{2}}(t)$ values of SST dipoles, and $\hat{\beta}^{i}$ represent the regression coefficients. In addition, a leave-one-out crossvalidation method (Elsnr and Schmertmann, 1994) is employed to avoid overfitting. Here, this method leaves one value (validation data) out at a time and uses the remaining data (calibration data) to establish the regression equation. The regression equation is then used to estimate the validation point. When the method is repeated $h$ times where $h$ is the data size, all the forecasted values are obtained using one of h different regression equations. The parameter $\xi$ is the number of significant SST dipoles sorted according to the lowest mean absolute error (MAE). The ensemble reliability (Re) reaches a maximum value when $\xi$ is about 20 (Chen and Georgakakos, 2013), so 20 significant SST dipoles are eventually selected to generate an ensemble range.

\subsection{Bias correction of GCM simulations}

The outputs of GCMs are too biased to be directly used at a regional scale (Crochemore et al., 2016; Chen et al., 2011). Therefore, the present work seeks to reduce the bias to an acceptable level by applying a simple linear scaling (LS) method (Mpelasoka and Chiew, 2009; Chen et al., 2013). The leave-one-out cross-validation method is again employed in the bias correction method. Specifically, GCM-simulated monthly rainfall for each validation year is scaled by the ratio of the GCM-simulated mean rainfall over all other years divided to the corresponding observed mean rainfall. After bias correction, all validation years are combined to construct the corrected time series. The bias-corrected rainfall is compared to the raw data to ascertain the performance of the bias correction method.

\subsection{Evaluation metrics}

To quantitatively evaluate the forecasting skill, several deterministic and ensemble metrics are used. They include three deterministic metrics, i.e., MAE, Mean relative error (MRE), and Pearson's correlation $(\rho)$, and four ensemble metrics, including Re, lower-minimum excess (LME) and upper-maximum excess (UME), and the ratio of mean width of an ensemble envelope to the observation range $(\gamma)$. The formulas and brief descriptions of these metrics are listed in Table 3 . Additional details regarding these metrics can be found in Chen and Georgakakos (2013).

\section{Results}

\subsection{Monthly forecasting accuracy}

\subsubsection{Monthly SST forecasting accuracy and SST dipole illustrations}

Tables S1 and S2 in the Appendix A list of the values of the forecasting accuracy metrics obtained using the SST statistical model for June to September rainfall at a given lead time of 1 to 12 months in the UYRB and LYRB. To assess the variations and relative magnitudes of these metrics, the MRE, R and Re values of different lead times are plotted in Fig. 2.

In general, the SST statistical model performs reasonably well with respect to forecasting June 
to September rainfall in the UYRB and LYRB. However, it performs better in the UYRB than in the LYRB for all four months. The lowest MRE is within 10\% for all four months in the UYRB, and within 15\% for June through August, and 20\% for September in the LYRB, as shown in Figs. 2a, b. In Figs. 2a, c, the lowest value of MRE (5.461\%) and the highest value of $\rho(0.664)$ are obtained at the 11-month lead time for June rainfall forecasting in the UYRB. For June rainfall forecasting in the LYRB, the highest prediction accuracy is obtained with the 4-month lead time which provides the lowest MRE and the highest $\rho(0.7)$. In this case, the best trace (using the best predicting dipole) explains $50 \%$ of the rainfall variance. Compared to the reasonably accurate June rainfall forecasts, July rainfall forecasting is less accurate with greater relative errors for both UYRB and LYRB. However, relatively good forecasting accuracy is obtained in July for both UYRB and LYRB at two lead times of 11 and 12 months, based on nearly all skill metrics. In Figs. 2a, c, e, the August rainfall forecasts in the UYRB obtained with 2 and 3-month lead times appear to provide better accuracy than forecasts obtained with longer lead times. Lastly, the rainfall forecasting accuracy in September is watershed dependent with the lowest MRE being equal to $8.5 \%$ for the UYRB and equal to $22 \%$ for the LYRB (Figs. 2a, b). The ensemble range of September rainfall exhibits a satisfactory performance in the UYRB, where the highest Re reaches about 0.8 and the best single trace accounts for $59 \%$ of the rainfall variance. However, rainfall in September cannot be well predicted in the LYRB, where the best-fitting time series exhibits large errors (Fig. 2b). In addition to these three metrics, in Table S2, it is worth noting that the values of UME obtained for June and July rainfall forecasts in the LYRB are obviously higher than those for other months. These high UME values in conjunction with the fact that LYRB experiences heavy rain in June and July, indicate that the SST statistical model fails to accurately forecast extreme rainfall events (e.g., the rainfall observed in 1998).

To understand how the deviations between the observed rainfall and the ensemble range are related to the SST dipoles, two different lead times that provide reasonably good forecasting accuracy for each month are displayed and the actual SST dipoles employed in the model construction are also investigated. The primary criterion for the selection of the two lead times of each month is that the corresponding forecasts must provide a relatively low MRE and either a high $\rho$ or Re. In addition, the two selected lead times for the UYRB should be similar to those for the LYRB to enable comparison. The time series of rainfall and their corresponding SST dipoles are respectively shown in Figs.3-4 for June rainfall and Fig. S1-S6 in Appendix B for July-September rainfall.

Fig.3a shows that the best-fitting forecasted time series for June rainfall agrees with observations reasonably well, with most of the observations included within the ensemble range. In Fig. 3c, the best predicting dipole locates in the tropical eastern region of the Pacific Ocean, which is a major ENSO region. Two other major dipole areas are in the Central to West Pacific and the middle latitude of the North Pacific. The Central to West Equatorial Pacific is usually considered as the complementary region of the ENSO. Compared with the 11-month lead time forecasting time series, the forecasted values for the 1-month lead forecasts overestimate the rainfall in dry years (e.g., 1988 and 2006). In this case, the central to West Equatorial Pacific, considered as the complementary region of ENSO, has changed from a positive pole in Fig.3c to a negative one in Fig.3d. The June rainfall in the LYRB exhibits large interannual variability, with rainfall values ranging from about 100 to $300 \mathrm{~mm}$ per month, which is quite difficult to capture when using the SST statistical model, as shown in Figs. 4a, b. The corresponding SST dipoles for the 11-month lead 
forecasts in both the UYRB and LYRB have roughly similar distribution. Therefore, the distribution of the dipoles for the 11-month lead time is more credible for forecasting June rainfall than the 1month (in the UYRB) or 3-month lead times (in the LYRB). In Figs. S1a, b, the accuracy of the July forecasting in the UYRB is better during wet years (e.g., 1984 and 1998) than dry years (e.g., 1994 and 2006). The distributions of the related SST dipoles are quite different between these two lead times. For the 11-month lead time, positive poles are located in the Western Indian Ocean and the ENSO region (in Figs. S1c, d). This may imply that the seasonal SST variation in the Indian Ocean is similar to that in the ENSO region. Regarding the forecasted time series in the LYRB shown in Figs. S2a, b, the forecasting accuracy associated with 12-month lead time appears to diminish after 1990, as reflected by the larger errors in the maxima and minima forecasted values. The related SST dipoles shown in Figs. S2c, d present similar patterns between two selected lead times, and are mainly located in the Central to West Pacific, surrounding the marine area of Australia.

For August, as shown in Figs. S3a, b, the rainfall forecasting for UYRB provided by the SST statistical model is unreliable in 1993 and 2006 for both lead times, indicating that the model is not sensitive to signals reflecting rainfall variability for specific wet or dry years. With regard to the LYRB, nearly half of observed values reside outside of the ensemble range due to low Re values for lead times of 2 and 7 months, as shown in Figs, S4a, b. Thus, relatively larger errors are observed for both the deterministic and ensemble metrics. However, it is notable that the dipole patterns (Figs. S3c, d and Figs.S4c, d) at the two lead times are similar for UYRB and LYRB. Here, the positive poles mainly appear in the Indian Ocean and the negative poles appear in the Pacific Ocean (except for the case of the 2-month lead time in the LYRB). The interaction of these two oceans determines the SSTA that influences the August rainfall in the Yangtze River basin.

For September, the forecasts for the two selected lead times (10 and 6 months) in the UYRB accurately capture the maxima and minima rainfall values, as shown in Figs. S5a, b, respectively. The corresponding SST dipoles shown in Figs.S5c, $d$ and Figs.S6c, $d$ for the UYRB and LYRB, present a wide distribution range, and are mainly distributed in the low latitudes of the Indian Ocean and the Eastern Pacific which are both near the mainland of Australia. Other significant dipoles are located in the middle latitudes of the Eastern Pacific which reside close to the coastlines. Significant dipoles are also frequently observed in this area during other months considered.

\subsubsection{Monthly GCM forecasting accuracy}

Table 4 lists the values of the forecasting accuracy metrics obtained using the four GCMs with and without bias correction for June rainfall at lead times of 0 and 1 months, in both the UYRB and the LYRB. The respective results of July to September rainfall are listed in Table S3 in the Appendix A.

As shown in Tables 4 and S3, among the four GCMs, CFSv2 provides the best prediction performance in the monthly forecast for both the UYRB and LYRB, while CMC2 provides the second best performance. In contrast, MOM3-AC and MOM3-DC exhibit modest prediction performance for all the four months. In general, the forecasting accuracy is improved to some degree after bias correction, with a large decrease in MAE and MRE for all months. In addition, the correlations between the predicted and observed monthly rainfall values are similar before and after bias correction. For example, bias correction has a pronounced effect for the MAE and MRE metrics of CFSv2, where the MAE decreases from 36.2 to $9.7 \mathrm{~mm}$ after bias correction and the MRE decreases from $36.4 \%$ to $9.4 \%$ for September rainfall in the UYRB with 0 -month lead time. These 
results demonstrate the validity of the bias correction method.

Fig. 5 is plotted to observe the variation of different values of $\rho$ among GCMs and lead times after bias correction. Values above the red lines (0.367) are significantly different from zero at a 5\% level (using a t-test). For the 0-month lead time, the best prediction accuracy is obtained for the UYRB in September with the highest $\rho$, followed by CMC2 (in Fig. 5a). The high correlation and error less than $10 \%$ indicate that CFSv2 provides reliable rainfall forecasting for the September in the UYRB with the 0-month lead time. Similar forecasting accuracy is obtained for CFSv2 during July and August in the UYRB, although CMC2 performs better than CFSv2 for forecasting August rainfall with higher $\rho$. For LYRB, the $\rho$ values for all GCMs are not significant for June, July and August rainfall, except for September rainfall (Fig. 5b). September rainfall predicted by CFSv2 and CMC2 shows a high $\rho(0.75)$, however, the bias correction method has little effect on the results (larger errors after bias correction shown in Table S3).

The forecasting accuracies of the GCMs obviously decrease when the lead time is extended to 1 month for both the UYRB and LYRB. For example, the four GCMs exhibit no predictive capabilities whatsoever for the 1-month lead time in the UYRB since the values of $\rho$ are all under a significant level. Overall superiority is obtained by CFSv2 for forecasting rainfall in the LYRB. Similarly, despite the relatively high $\rho$, the bias correction method has little effect on improving the forecasting accuracy (e.g., MRE $=19.7 \%$ for raw $\mathrm{CFSv} 2$ data, but $\mathrm{MRE}=29.9 \%$ under bias correction in Table S3 in Appendix A).

\subsection{Seasonal forecasting accuracy}

\subsubsection{Seasonal SST forecasting accuracy and SST dipole illustrations}

The seasonal forecasting accuracy of the SST statistical model is evaluated for two seasons (JJA and JAS) to further investigate its timescale dependence. The forecasting accuracies for JJA and JAS rainfall are listed in Table S4 for the UYRB and LYRB, while the three metrics (MRE, R and $\mathrm{Re}$ ) are plotted in Fig. 6.

The results in Fig.6 indicate that the SST statistical model forecasts JJA and JAS rainfall in the UYRB with better accuracy for shorter lead times. The best forecasting accuracy of JJA rainfall is obtained with the 1-month lead time (i.e. when MAM SSTs are used to forecast JJA rainfall), as indicated by the optimum metric values obtained for all three metrics. The forecasting model exhibits good forecasting accuracy for JAS rainfall in the UYRB with a Re value of 0.72 (1-month lead time) and a $\rho$ value of 0.66 (2-month lead time). For the LYRB, the lowest MRE values of the JJA and JAS rainfall forecasts are less than $10 \%$. JAS rainfall in the LYRB is better forecasted at longer lead times of 9 to 12 months, and the Re value reaches up to 0.8 . Notably, the most skillful lead times providing the greatest accuracy are also concentrated on a seasonal scale ( 3 consecutive months or more), which is consistent with the monthly forecasts.

The seasonal forecasting rainfall time series obtained in the UYRB and LYRB for JJA and JAS are also compared with two different lead times, and again investigate the actual SST dipoles employed in the model construction. The forecasted and observed rainfall time series and their corresponding SST dipoles are respectively shown in Figs. 7-8 for JJA rainfall and Figs. S7-S8 in Appendix B for JAS rainfall.

For JJA rainfall in the UYRB, Figs. 7a, b indicate the better predictions of the maxima and minima rainfall values are obtained with 7-month lead time than those with 5 -month lead time in 
the 1980s and 1990s, while the opposite situation is observed in the 2000s. This indicates that the JJA rainfall over different years is sensitive to the SSTA associated with different lead times. As shown in Figs. 7c, d, the SST dipoles associated with the 7-month lead time are mainly located in the Eastern Pacific Ocean which is near the ENSO region, and dipoles associated with the 5-month lead time are located off the east coast of Australia. As for JJA rainfall over the LYRB shown in Figs. $8 \mathrm{a}, \mathrm{b}$, the best forecasted time series exhibit large fluctuations, and yet cannot fit the observations due to their large interannual variability, particularly for the very wet years (e.g., 1996 and 1998). For those two lead times, the most significant dipoles in Figs. 8c, d are separately distributed in the Central Pacific Ocean and the Indian Ocean, which is completely different from the dipole distributions associated with JJA rainfall in the UYRB.

As shown in Figs. S7a, b, a large proportion of the minima rainfall values falls outside of the lower ensemble boundary for JAS rainfall in the UYRB with both lead times of 7 and 10 months, while the upper ensemble boundary typically encompasses the maxima values for JAS rainfall. This is particularly significant for the rainfall value observed in 1998, which is successfully captured by the upper ensemble boundary with 9-month lead time (Fig. S7a). This implies that the seasonal forecasts may provide better guidance for flood control than for drought control. In terms of the SST dipoles shown in Figs. S7c, d, the dipoles obtained with a 10-month lead time for the JAS are mainly located in middle latitudes of the Central to East Pacific Ocean. As for JAS rainfall over the LYRB shown in Figs. S8a, b, the high values of Re obtained for the forecasted JAS rainfall with a lead time of 10 months indicate that the ensemble range provided here is more accurate than that obtained for JJA rainfall. However, the best forecasted time series obtained for JAS rainfall in the LYRB cannot capture the observed maxima values. In contrast, acceptable performance is obtained for predicting rainfall during dry years (e.g., 1990 and 1992). Finally, a comparison of the SST dipoles associated with JAS forecasting in the LYRB with a 10-month lead time (Fig. S8d) is very similar to those in the UYRB (Fig. S7d).

\subsubsection{Seasonal GCM forecasting accuracy}

Table 5 lists the values of the seasonal forecasting accuracy metrics obtained using four GCMs with and without bias correction at lead times of 0 and 1 months in both the UYRB and LYRB for JJA rainfall. The respective forecasting accuracies for JAS rainfall are listed in Table S5 in Appendix A.

As shown in Tables 5 and S5, the seasonal rainfall forecasts of the four GCMs are more accurate than the monthly forecasts in terms of the MAE and MRE values, but the maximum values of $\rho$ are less than those obtained for monthly forecasts. In Fig.9, almost all of the $\rho$ values (after bias correction) are under the significant line, indicating the poor abilities of the GCMs for seasonal forecasts. JAS rainfall ( 0 -month lead time) forecasted by CFSv2 and CMC2 provides relatively high $\rho$ values and reasonable MRE values (shown in Table S5), which can provide some useful information for decision-makers. When the lead time is extended to 1 month, all the four GCMs exhibit no predictive capabilities whatsoever (shown in Fig. 9b). 


\section{Discussion}

\subsection{Analysis of the dipole-based statistical model}

In general, the results of this study have demonstrated that the SST statistical model performs better for seasonal forecasts than for monthly forecasts. This may be because the monthly forecasts involve a time period that is too short to respond adequately to variability in oceanic variables like SST. Also, the lead times providing relatively satisfactory forecasting performance often appear at a seasonal timescale (three consecutive months or more) for both seasonal and monthly forecasting. Previous studies (e.g. Wang et al., 2001) have demonstrated that the influence of ENSO events is two to three seasons later than the East Asian summer circulation. The most significant SST dipoles associated with the forecasting results are distributed mainly in two regions: the Central to Eastern Pacific Ocean, particularly the ENSO region, and the tropical Equatorial Indian Ocean. In addition, some dipoles are located in the complementary region of the ENSO, i.e., the Central to West Equatorial Pacific. A number of previous studies (e.g., Ashok et al., 2003) have found that the SSTA locations in the tropical Indian Ocean cause the climate anomalies in neighboring areas. However, SSTA locations in the Indian Ocean do not represent a completely independent system and are in close contact with the Pacific Ocean through the Walker circulation and other processes (Ashok et al., 2003; Stuecker et al., 2017). Therefore, a reasonable approach for considering the impact of SSTA locations on rainfall in the Yangtze River basin is to consider the effects of SSTA locations in the tropical Pacific and tropical Indian Oceans. The dipole search algorithm employed in the present work capitalizes on these considerations by capturing the process of changing ocean interactions at different lead times for different target months or seasons. Another similar method called Empirical Orthogonal Teleconnections (EOT) has been applied in China (Stephan et al., 2017a, 2017b, 2018). This method aims at looking for SST regions which have strong teleconnection with rainfall regions in China. Specifically, it uses linear regressions to search for a point (the base point) in space as the predictor that explains the most of the variance over all other points, then the first EOT time series (at the base point) is removed and the above steps are repeated to compute the second, third, ... and all other EOTs. The EOTs can then be used to establish the regression maps of SST to link the rainfall variability to large-scale dynamical mechanisms (such as ENSO). The advantage of this method is that it can create forecasts for only a few selected rainfall base points when used for rainfall forecasts over large regions. However, the EOT patterns are only dominated by monopoles rather than dipolar patterns, so the interaction between different Ocean areas are not taken into account. The dipole-based statistical model employed in this study aims to reveal this interaction and then establishes the teleconnection relationship between the variation of different ocean areas and the rainfall region.

\subsection{Uncertainty of GCMs}

The results demonstrate that the differences between the forecasting accuracies of the different GCMs are significant. Generally, the raw GCM forecasts provide limited rainfall information. After bias correction, CFSv2 typically outperforms the other three models with overall better $\rho$, MAE, or MRE values for both monthly and seasonal forecasts. However, CMC2 occasionally provides superior forecasting performance. While CFSv2 and CMC2 present reliable rainfall forecasting performance at the 0 -month lead time in the UYRB, particularly for July and 
September, the sharply decreasing forecasting reliabilities of all four GCMs obtained when the lead time is extended to one month indicates that a single model has limited forecasting capability for the Yangtze River basin when the lead time is longer than 1 month. In fact, many GCMs share similar atmospheric and oceanic components, which may explain why they exhibit similar trends with respect to the prediction capabilities associated with longer lead times (Givati et al., 2017). Some studies have also shown that an ensemble of models performs better than any single model (Kirtman et al., 2014, Li and Lin, 2015). Thus, the use of a multimodel ensemble that combines the benefits of several GCMs may provide higher predictive performance for monthly and seasonal forecasts.

\subsection{Analysis of SST and GCM forecasting advantages and potential for integration}

Improved guidance for forecasting the monsoon rainfall in the Yangtze River basin may be provided by integrating the distinct prediction performances of the SST statistical model and the four dynamical GCMs. The SST statistical model provides relatively accurate rainfall forecasts and longer forecasting periods with lead times of up to 12 months. The forecast ensembles obtained by the model provide a prediction interval rather than a single deterministic value. However, changes in the SST mechanism affecting rainfall patterns in the Yangtze River basin can alter the most advantageous lead time. In contrast, the forecasting capability of GCMs is unsatisfactory when the lead time is extended beyond 1 month, particularly in the LYRB. However, CFSv2 and CMC2 can provide robust forecasting within the 0 -month lead time. Therefore, GCMs can serve as a reference if rainfall forecasts in the coming month or coming season are needed because the short-lead-time performance of these models is definitely better than that of long lead times, while the SST statistical model can provide more stable rainfall forecasts for a lead time longer than 1 month. Forecasting based on GCMs is also much more dependent on the location of the region of interest than the statistical model, which is a very important consideration when predicting rainfall in the UYRB and LYRB. However, the SST statistical model can maintain practical and credible forecasting capabilities in both the UYRB and LYRB. In this regard, the forecasting capabilities of the SST statistical model can be combined with those of GCMs to conduct more accurate rainfall forecasting for the Yangtze River basin, particularly when short lead times are involved. Meanwhile, the SST statistical model would be the primary choice for forecasting monthly and seasonal rainfall in the Yangtze River basin when considering long lead times.

Even though this study compared the forecasting accuracies of the dynamical models and the SST statistical model, both methods are separately evaluated. The best solution should combine advantages of both methods. In fact, some previous studies have tried to combine these two types of models to strengthen the ability of seasonal forecast. Some involve the outputs of dynamical GCMs (for example, the Met Office's GloSea5 system) to statistically make the seasonal rainfall forecasting. Specifically, these studies applied linear regression model to the indirect GloSea5 hindcasts (e.g, the mean sea-level pressure) or the direct forecasts of precipitation of the GloSea5 system to statistically predict regional rainfall (Baker et al., 2018; Bett et al., 2018). Other approaches have applied some complex statistical techniques such as neural networks to the large scale driver outputs from dynamical models to forecast rainfall (Hartmann et al., 2008; Mekanik et al., 2013). These statistical-dynamical techniques can be applied to further studies to strengthen the prediction ability of the SST statistical model or the raw GCM outputs. This can be an avenue for future studies. 
509

\section{Conclusions}

This study has applied a statistical model based on SST dipoles and four GCMs with and without bias correction to forecast monsoon rainfall in the Yangtze River basin at monthly and seasonal timescales. The SST statistical model searches the most significant dipoles as the predictor and establishes a statistical relationship between the SST dipoles and monsoon rainfall. The analysis provides the following conclusions.

(1) The SST statistical model demonstrates a stable forecasting capability for the four monthly and two seasonal periods. The best value of $\rho$ is 0.75 and the lowest MRE is less than $6 \%$. The highest $\operatorname{Re}(0.83)$ represents a strong ensemble performance of the ensemble range. The dipole search algorithm successfully identifies the most significant dipoles presenting the locations and interconnection relationships of the SST poles. Interactions between the Eastern Pacific Ocean, Central to West Equatorial Pacific, the Indian Ocean and the atmospheric circulation possibly influence the rainfall in the Yangtze River basin.

(2) The differences between the forecasting accuracies of the four GCMs are significant. After bias correction, CFSv2 generally outperforms the other three GCMs, while CMC2 occasionally provides the superior forecasting performance. The best value of $\rho$ obtained by CFSv2 is 0.78 and the lowest MRE is $9.4 \%$ for September rainfall in the UYRB, however, the forecasting capabilities of all four GCMs decrease sharply when the lead time is extended to 1 month.

(3) The forecasting capabilities of the SST statistical model and four GCMs can provide the guidance for conducting monthly and seasonal rainfall forecasts in the Yangtze River basin. The SST statistical model provides more stable forecasting capability than the GCMs, owing to the overall better values obtained for forecasting evaluation metrics and the longer lead time provided. For short lead times (no longer than one month), CFSv2 and CMC2 provide some forecasting capabilities that are comparable with that of the SST statistical model, for example, for the September rainfall in the UYRB. For longer lead times, the SST statistical model is more credible for its stable rainfall forecasting performance. A combination of these two types of models may be more reliable for water resource management activities when conducted with a relatively short lead time.

\section{Acknowledgements:}

This work was partially supported by the National Natural Science Foundation of China (Grant No .51779176, 51539009), the Overseas Expertise Introduction Project for Discipline Innovation (11 1 Project) funded by Ministry of Education and State Administration of Foreign Experts Affairs P. R. China (Grant No. B18037) and the Thousand Youth Talents Plan from the Organization Depart ment of CCP Central Committee (Wuhan University, China).

\section{Reference:}

Acharya, N., Chattopadhyay, S., Mohanty, U. C., and Ghosh, K. (2014). Prediction of Indian summer monsoon rainfall: a weighted multi-model ensemble to enhance probabilistic forecast skills. Meteorological Applications, 21(3), 724-732. https://doi.org/10.1002/met.1400 
Alessandri, A., Borrelli, A., Navarra, A., Arribas, A., Déqué, M., Rogel, P., and Weisheimer, A. (2011). Evaluation of probabilistic quality and value of the ensembles multimodel seasonal forecasts: Comparison with DEMETER. Monthly Weather Review, 139(2), 581-607. https://doi.org/10.1175/2010mwr3417.1

Alfieri, L., Burek, P., Dutra, E., Krzeminski, B., Muraro, D., Thielen, J., and Pappenberger, F. (2013). GloFAS-global ensemble streamflow forecasting and flood early warning. Hydrology and Earth System Sciences, 17(3), 1161-1175. https://doi.org/10.5194/hess-17-1161-2013

Ashok, K., Guan, Z., and Yamagata, T. (2003). Influence of the Indian Ocean Dipole on the Australian winter rainfall. Geophysical Research Letters, 30, 1821. https://doi.org/10.1029/2003GL017926

Ashok, K., Guan, Z., and Yamagata, T. (2003). A Look at the relationship between the ENSO and the Indian Ocean Dipole. Journal of the Meteorological Society of Japan, 81(1), 41-56. https://doi.org/10.2151/jmsj.81.41

Badr, H. S., Zaitchik, B. F., and Guikema, S. D. (2014). Application of Statistical Models to the Prediction of Seasonal Rainfall Anomalies over the Sahel. Journal of Applied Meteorology and Climatology, 53(3), 614-636. https://doi.org/10.1175/jamc-d-13-0181.1

Baker, L. H., Shaffrey, L. C., and Scaife, A. A. (2018). Improved seasonal prediction of UK regional precipitation using atmospheric circulation. International Journal of Climatology, 38, e437-e453. https://doi.org/10.1002/joc.5382

Bett, P. E., Scaife, A. A., Li, C., Hewitt, C., Golding, N., Zhang, P., et al. (2018). Seasonal Forecasts of the Summer 2016 Yangtze River Basin Rainfall. Advances in Atmospheric Sciences, 35(8), 918-926. https://doi.org/10.1007/s00376-018-7210-y

Birkinshaw, S. J., Guerreiro, S. B., Nicholson, A., Liang, Q., Quinn, P., Zhang, L., et al. (2017). Climate change impacts on Yangtze River discharge at the Three Gorges Dam. Hydrology and Earth System Sciences, 21(4), 1911-1927. https://doi.org/10.5194/hess-21-1911-2017

Cao, Q., Hao, Z., Yuan, F., Su, Z., and Berndtsson, R. (2017). ENSO Influence on Rainy Season Precipitation over the Yangtze River Basin. Water, 9(7), 469. https://doi.org/10.3390/w9070469

Chen, C-J., Georgakakos, A. P. (2013). Hydro-climatic forecasting using sea surface temperatures: methodology and application for the southeast US. Climate Dynamics, 42(11-12), 29552982. https://doi.org/10.1007/s00382-013-1908-4

Chen, C.-J., Georgakakos, A. P. (2015). Seasonal prediction of East African rainfall. International Journal of Climatology, 35(10), 2698-2723. https://doi.org/10.1002/joc.4165

Chen, J., Brissette, F. P., Chaumont, D., and Braun, M. (2013). Performance and uncertainty evaluation of empirical downscaling methods in quantifying the climate change impacts on hydrology over two North American river basins. Journal of Hydrology, 479, 200-214. https://doi.org/10.1016/j.jhydrol.2012.11.062

Chen, J., Brissette, F. P., and Leconte, R. (2011). Uncertainty of downscaling method in quantifying the impact of climate change on hydrology. Journal of Hydrology, 401(3-4), 190-202. https://doi.org/10.1016/j.jhydrol.2011.02.020

Ciancarelli, B., Castro, C. L., Woodhouse, C., Dominguez, F., Chang, H.-I., Carrillo, C., and Griffin, D. (2014). Dominant patterns of US warm season precipitation variability in a fine resolution observational record, with focus on the southwest. International Journal of Climatology, 34(3), 687-707. https://doi.org/10.1002/joc.3716 
Crochemore, L., Ramos, M.-H., and Pappenberger, F. (2016). Bias correcting precipitation forecasts to improve the skill of seasonal streamflow forecasts. Hydrology and Earth System Sciences, 20(9), 3601-3618. https://doi.org/10.5194/hess-20-3601-2016

Deng, H., Luo, Y., Yao, Y., and Liu, C. (2013). Spring and summer precipitation changes from 1880 to 2011 and the future projections from CMIP5 models in the Yangtze River Basin, China. Quaternary International, 304, 95-106. https://doi.org/10.1016/j.quaint.2013.03.036

Ding, Y., Wang, Z., and Sun, Y. (2008). Inter-decadal variation of the summer precipitation in East China and its association with decreasing Asian summer monsoon.Part I: Observed evidences. International Journal of Climatology, 28(9), 1139-1161. https://doi.org/10.1002/joc.1615

Dirmeyer, P. A., and Halder, S. (2017). Application of the Land-Atmosphere Coupling Paradigm to the Operational Coupled Forecast System, Version 2 (CFSv2). Journal of Hydrometeorology, 18(1), 85-108. https://doi.org/10.1175/jhm-d-16-0064.1

Elsner, J. B., and Schmertmann, C. P. (1994). Assessing forecast skill through cross validation. Weather and Forecasting, 9(4), 619-624. https://doi.org/10.1175/15200434(1994)009<0619:AFSTCV>2.0.CO;2

Gerrity, J. P. (1992). A note on Gandin and Murphy's equitable skill score. Monthly Weather Review, 120(11), 2709-2712. https://doi.org/10.1175/15200493(1992)120<2709:ANOGAM>2.0.CO;2

Givati, A., Housh, M., Levi, Y., Paz, D., Carmona, I., and Becker, E. (2017). The Advantage of Using International Multimodel Ensemble for Seasonal Precipitation Forecast over Israel. Advances in Meteorology, 2017, 1-11. https://doi.org/10.1155/2017/9204081

Hardiman, S. C., Dunstone, N. J., Scaife, A. A., Bett, P. E., Li, C., Lu, B., et al (2018). The asymmetric response of Yangtze river basin summer rainfall to El Niño/La Niña. Environmental Research Letters, 13(2), 024015. https://doi.org/10.1088/1748-9326/aaa172

Hartmann, H., Becker, S., and King, L. (2008). Predicting summer rainfall in the Yangtze River basin with neural networks. International Journal of Climatology, 28(7), 925-936. https://doi.org/10.1002/joc. 1588

Hui, G., Yongguang, W., and Jinhai, H. (2006). Weakening significance of ENSO as a predictor of summer precipitation in China. Geophysical Research Letters, 33(9), 209807. https://doi.org/10.1029/2005g1025511

Jiang, T., Kundzewicz, Z. W., and Su, B. (2008). Changes in monthly precipitation and flood hazard in the Yangtze River Basin, China. International Journal of Climatology, 28(11), 14711481. https://doi.org/10.1002/joc.1635

Kaplan, A., Cane, M. A., Kushnir, Y., Clement, A. C., Blumenthal, M. B., and Rajagopalan, B. (1998). Analyses of global sea surface temperature 1856-1991. Journal of Geophysical Research Oceans, 103(C9), 18567-18589. https://doi.org/10.1029/97JC01736

Kim, H.-M., Webster, P. J., amd Curry, J. A. (2012). Seasonal prediction skill of ECMWF System 4 and NCEP CFSv2 retrospective forecast for the Northern Hemisphere Winter. Climate Dynamics, 39(12), 2957-2973. https://doi.org/10.1007/s00382-012-1364-6

Kirtman, B. P., Min, D., Infanti, J. M., Kinter, J. L., Paolino, D. A., Zhang, Q., et al. (2014). The North American Multimodel Ensemble: Phase-1 Seasonal-to-Interannual Prediction; Phase-2 toward Developing Intraseasonal Prediction. Bulletin of the American Meteorological Society, 95(4), 585-601. https://doi.org/10.1175/bams-d-12-00050.1 
Krishna Kumar, K. (2005). Advancing dynamical prediction of Indian monsoon rainfall. Geophysical Research Letters, 32(8), 216-225. https://doi.org/10.1029/2004g1021979

Lang, Y., Ye, A., Gong, W., Miao, C., Di, Z., Xu, J., et al. (2014). Evaluating Skill of Seasonal Precipitation and Temperature Predictions of NCEP CFSv2 Forecasts over 17 Hydroclimatic Regions in China. Journal of Hydrometeorology, 15(4), 1546-1559. https://doi.org/10.1175/jhm-d-13-0208.1

Li, C., Scaife, A. A., Lu, R., Arribas, A., Brookshaw, A., Comer, R. E.,et al. (2016). Skillful seasonal prediction of Yangtze river valley summer rainfall. Environmental Research Letters, 11(9), 094002. https://doi.org/10.1088/1748-9326/11/9/094002

Li, F., and Lin, Z. (2015). Improving multi-model ensemble probabilistic prediction of Yangtze River valley summer rainfall. Advances in Atmospheric Sciences, 32(4), 497-504. https://doi.org/10.1007/s00376-014-4073-8

McGregor, G. R., and Phillips, I. D. (2004). Specification and prediction of monthly and seasonal rainfall over the south-west peninsula of England. Quarterly Journal of the Royal Meteorological Society, 130(596), 193-210. https://doi.org/10.1256/qj.03.10

Mekanik, F., Imteaz, M. A., Gato-Trinidad, S., and Elmahdi, A. (2013). Multiple regression and Artificial Neural Network for long-term rainfall forecasting using large scale climate modes. Journal of Hydrology, 503, 11-21. https://doi.org/10.1016/j.jhydrol.2013.08.035

Mpelasoka, F. S., and Chiew, F. H. S. (2009). Influence of Rainfall Scenario Construction Methods on Runoff Projections. Journal of Hydrometeorology, 10(5), 1168-1183. https://doi.org/10.1175/2009jhm1045.1

Murphy, A. H., (1993). What is a good forecast? an essay on the nature of goodness in weather forecasting. Weather and Forecasting, 8(2), 281-293. https://doi.org/10.1175/15200434(1993)008<0281:WIAGFA $>2.0 . C O ; 2$

Peng, Z., Wang, Q. J., Bennett, J. C., Schepen, A., Pappenberger, F., Pokhrel, P., and Wang, Z. (2014). Statistical calibration and bridging of ECMWF System4 outputs for forecasting seasonal precipitation over China. Journal of Geophysical Research: Atmospheres, 119(12), 71167135. https://doi.org/10.1002/2013jd021162

Pokhrel, S., Saha, S. K., Dhakate, A., Rahman, H., Chaudhari, H. S., Salunke, K., et al. (2015). Seasonal prediction of Indian summer monsoon rainfall in NCEP CFSv2: forecast and predictability error. Climate Dynamics, 46(7-8), 2305-2326. https://doi.org/10.1007/s00382-015-2703-1

R. Pattanaik, D., Mukhopadhyay, B., and Kumar, A. (2012). Monthly Forecast of Indian Southwest Monsoon Rainfall Based on NCEP's Coupled Forecast System. Atmospheric and Climate Sciences, 02(04), 479-491. https://doi.org/10.4236/acs.2012.24042

Sittichok, K., Djibo, A. G., Seidou, O., Saley, H. M., Karambiri, H., and Paturel, J. (2016). Statistical seasonal rainfall and streamflow forecasting for the Sirba watershed, West Africa, using sea-surface temperatures. Hydrological Sciences Journal, 61(5), 805-815. https://doi.org/10.1080/02626667.2014.944526

Smith, D. M., Scaife, A. A., and Kirtman, B. P. (2012). What is the current state of scientific knowledge with regard to seasonal and decadal forecasting? Environmental Research Letters, 7(1), 015602. https://doi.org/10.1088/1748-9326/7/1/015602

Stephan, C. C., Klingaman, N. P., Vidale, P. L., Turner, A. G., Demory, M.-E., and Guo, L. (2017a). A comprehensive analysis of coherent rainfall patterns in China and potential drivers. Part 
682

683

684

685

686

687

688

689

690

691

692

693

694

695

696

697

698

699

700

701

702

703

704

705

706

707

708

709

710

711

712

713

714

715

716

I: Interannual variability. Climate Dynamics, $50(11-12), \quad 4405-4424$.
https://doi.org/10.1007/s00382-017-3882-8

Stephan, C. C., Klingaman, N. P., Vidale, P. L., Turner, A. G., Demory, M.-E., and Guo, L. (2017b). A comprehensive analysis of coherent rainfall patterns in China and potential drivers. Part II: intraseasonal variability. Climate Dynamics, 51(1-2), 17-33. https://doi.org/10.1007/s00382-017-3904-6

Stephan, C. C., Ng, Y. H., and Klingaman, N. P. (2018). On Northern Hemisphere Wave Patterns Associated with Winter Rainfall Events in China. Advances in Atmospheric Sciences, 35(8), 1021-1034. https://doi.org/10.1007/s00376-018-7267-7

Stuecker, M. F., Timmermann, A., Jin, F.-F., Chikamoto, Y., Zhang, W., Wittenberg, A. T., et al. (2017). Revisiting ENSO/Indian Ocean Dipole phase relationships. Geophysical Research Letters, 44(5), 2481-2492. https://doi.org/10.1002/2016gl072308

Tippett, M. K., and Delsole, T. (2013). Constructed analogs and linear regression. Monthly Weather Review, 141(7), 2519-2525. https://doi.org/10.1175/MWR-D-12-00223.1

Viana, D. R., and Sansigolo, C. A. (2016). Monthly and Seasonal Rainfall Forecasting in Southern Brazil Using Multiple Discriminant Analysis. Weather and Forecasting, 31(6), 1947-1960. https://doi.org/10.1175/waf-d-15-0155.1

Vitart, F. (2014). Evolution of ECMWF sub-seasonal forecast skill scores. Quarterly Journal of the Royal Meteorological Society, 140(683), 1889-1899. https://doi.org/10.1002/qj.2256

Wang, B., Lee, J.-Y., Kang, I.-S., Shukla, J., Park, C. K., Kumar, A., et al. (2008). Advance and prospectus of seasonal prediction: assessment of the APCC/CliPAS 14-model ensemble retrospective seasonal prediction (1980-2004). Climate Dynamics, 33(1), 93-117. https://doi.org/10.1007/s00382-008-0460-0

Wang, B., and Zhang, Q. (2002). Pacific-east Asian teleconnection. Part II: how the Philippine sea anomalous anticyclone is established during EI niño development. Journal of Climate, 15(22), 3252-3265. https://doi.org/10.1175/15200442(2002)015<3252:PEATPI $>2.0 . C O ; 2$

Wang, L., Yuan, X., Ting, M., and Li, C. (2016). Predicting Summer Arctic Sea Ice Concentration Intraseasonal Variability Using a Vector Autoregressive Model. Journal of Climate, 29(4), 1529-1543. https://doi.org/10.1175/jcli-d-15-0313.1

Wang, W., Chen, M., and Kumar, A. (2010). An Assessment of the CFS Real-Time Seasonal Forecasts. Weather and Forecasting, 25(3), 950-969. https://doi.org/10.1175/2010waf2222345.1

Wang Y., Wang Bin., Jai-Ho Oh. (2001). Impact of proceeding El Nino on the East Asian summer atmosphere circulation. Journal of the Meteorological Society of Japan, 79: 575-588. https://doi.org/10.2151/jmsj.79.575

Wetterhall, F., Winsemius, H. C., Dutra, E., Werner, M., and Pappenberger, E. (2015). Seasonal predictions of agro-meteorological drought indicators for the Limpopo basin. Hydrology and Earth System Sciences, 19(6), 2577-2586. https://doi.org/10.5194/hess-19-2577-2015

Wilks, D. S. (2008). Improved statistical seasonal forecasts using extended training data. International Journal of Climatology, 28(12), 1589-1598. https://doi.org/10.1002/joc.1661

Wu, X., Guo, S., Yin, J., Yang, G., Zhong, Y., and Liu, D. (2018). On the event-based extreme precipitation across China: Time distribution patterns, trends, and return levels. Journal of Hydrology, 562, 305-317. https://doi.org/10.1016/j.jhydrol.2018.05.028 
Wu, X., Wang, Z., Guo, S., Liao, W., Zeng, Z., and Chen, X. (2017). Scenario-based projections of future urban inundation within a coupled hydrodynamic model framework: A case study in Dongguan City, China. Journal of Hydrology, 547, 428-442. https://doi.org/10.1016/j.jhydrol.2017.02.020

Yuan, X., Wood, E. F., Luo, L., \& Pan, M. (2011). A first look at Climate Forecast System version 2 (CFSv2) for hydrological seasonal prediction. Geophysical Research Letters, 38(13), 17. https://doi.org/10.1029/2011GL047792

Yuan, X., Wood, E. F., Roundy, J. K., and Pan, M. (2013). CFSv2-Based Seasonal Hydroclimatic Forecasts over the Conterminous United States. Journal of Climate, 26(13), 4828-4847. https://doi.org/10.1175/jcli-d-12-00683.1

Zhao, T., Liu, P., Zhang, Y., and Ruan, C. (2017). Relating anomaly correlation to lead time: Clustering analysis of CFSv2 forecasts of summer precipitation in China. Journal of Geophysical Research: Atmospheres, 122(17), 9094-9106. https://doi.org/10.1002/2017jd027018 
775 Table 1. NMME partner models employed in the present study and their corresponding

776 forecasting information

\begin{tabular}{|c|c|c|c|c|c|c|c|c|}
\hline Model & $\begin{array}{l}\text { Hindcasting } \\
\text { period }\end{array}$ & Resolution & $\begin{array}{l}\text { Ensemble } \\
\text { size }\end{array}$ & $\begin{array}{l}\text { Lead times } \\
\text { (months) }\end{array}$ & \multicolumn{3}{|c|}{$\begin{array}{l}\text { Arrangement of } \\
\text { ensemble members }\end{array}$} & Reference \\
\hline CFSv2 & $1982-2010$ & $1^{\circ} \times 1^{\circ}$ & $24(28)$ & $0.5-9.5$ & \multicolumn{3}{|c|}{$\begin{array}{l}\text { Four members }(0000, \\
0600,1200 \text {, and } 1800 \\
\text { UTC every fifth day }\end{array}$} & $\begin{array}{l}\text { Saha et al., } \\
2014\end{array}$ \\
\hline $\begin{array}{l}\text { IRI-MOM3- } \\
\text { AC }\end{array}$ & $1982-2010$ & $1^{\circ} \times 1^{\circ}$ & 12 & $0.5-7.5$ & \multicolumn{3}{|c|}{$\begin{array}{l}\text { All first of the } \\
\text { month } 0000 \text { UTC }\end{array}$} & DeWitt 2005 \\
\hline \multirow{2}{*}{$\begin{array}{l}\text { IRI-MOM3- } \\
\text { DC } \\
\text { CMC2- } \\
\text { CanCM4 }\end{array}$} & $1982-2010$ & $1^{\circ} \times 1^{\circ}$ & 12 & $0.5-7.5$ & \multicolumn{3}{|c|}{$\begin{array}{l}\text { All first of the } \\
\text { month } 0000 \text { UTC }\end{array}$} & DeWitt 2005 \\
\hline & $1981-2010$ & $1^{\circ} \times 1^{\circ}$ & 10 & $0.5-11.5$ & \multicolumn{3}{|c|}{$\begin{array}{l}\text { All first of the } \\
\text { month } 0000 \text { UTC }\end{array}$} & $\begin{array}{l}\text { Merryfield } \\
\text { et al., } 2013\end{array}$ \\
\hline \multicolumn{9}{|l|}{777} \\
\hline \multicolumn{9}{|c|}{778} \\
\hline \multicolumn{9}{|l|}{$79 \quad$ Table 2.} \\
\hline $\begin{array}{l}\text { Data size } \\
\text { (h) }\end{array}$ & $\begin{array}{l}\text { Predictor } \\
\text { description }\end{array}$ & $\begin{array}{l}\text { Predictal } \\
\text { descripti }\end{array}$ & & $\begin{array}{l}\text { per threshold } \\
\text { stering pixels }\end{array}$ & & $\begin{array}{l}G_{S S} S_{R, \alpha} \\
=0.05 \\
\end{array}$ & $\xi$ & Lead times \\
\hline $\begin{array}{l}29(1982- \\
2010)\end{array}$ & $\begin{array}{l}\text { Kaplan SSTA } \\
{\left[65^{\circ} \mathrm{S}-65^{\circ} \mathrm{N},\right.} \\
\left.35^{\circ} \mathrm{E}-285^{\circ} \mathrm{E}\right]\end{array}$ & $\begin{array}{l}\text { JJAS rain } \\
\text { at UYRB }\end{array}$ & $\begin{array}{l}\text { all } \\
\text { CYRB }\end{array}$ & {$[p=q=10]$} & & 0.25 & 20 & $\begin{array}{r}1,2, \ldots, 12 \\
\text { (months) }\end{array}$ \\
\hline
\end{tabular}

\section{0}


801

802

803

804

805

Table 3. Specific formulas for forecasting accuracy metrics

\begin{tabular}{|c|c|c|}
\hline Measures & Formulas & Description \\
\hline \multicolumn{3}{|c|}{$\sum_{j=1}^{h}\left(f_{j}-\bar{f}\right)\left(o_{j}-\bar{o}\right)$} \\
\hline$\rho$ & $=\sqrt{\sqrt{\sum_{j=1}^{h}\left(f_{j}-\bar{f}\right)^{2}} \sqrt{\sum_{j=1}^{h}\left(o_{j}-\bar{o}\right)^{2}}}$ & Pearson's correlation \\
\hline MAE & MAE $=\frac{1}{h} \sum_{j=1}^{h}\left|f_{j}-o_{j}\right|$ & Mean absolute error \\
\hline MRE & MRE $=\frac{1}{h} \sum_{j=1}\left|f_{j}-o_{j}\right| / o_{j}$ & Mean relative error \\
\hline $\operatorname{Re}$ & $\operatorname{Re}=\frac{1}{h} \sum_{j=1}^{h} I_{F_{j}}\left(o_{j}\right), \quad I_{F_{j}}\left(o_{j}\right)=\left\{\begin{array}{lll}1 & \text { if } & o_{j} \in F_{j} \\
0 & \text { if } & o_{j} \notin F_{j}\end{array}\right.$ & $\begin{array}{l}\text { Number of data points } \\
\text { observed within ensemble } \\
\text { range. }\end{array}$ \\
\hline LME & $\mathrm{LME}=\min \left(o_{j}-\min \left(f_{j}\right) \mid o_{j}<\min \left(f_{j}\right)\right)$ & Largest difference between \\
\hline UME & $\mathrm{UME}=\max \left(o_{j}-\max \left(f_{j}\right) \mid o_{j}>\max \left(f_{j}\right)\right)$ & $\begin{array}{l}\text { the observed data and the } \\
\text { ensemble range. }\end{array}$ \\
\hline$\gamma$ & $\gamma=\frac{\frac{1}{h} \sum_{j=1}^{h}\left(\max \left(f_{j}\right)-\min \left(f_{j}\right)\right)}{\max \left(o_{j}\right)-\min \left(o_{j}\right)}$ & $\begin{array}{l}\text { Similarity of the ensemble } \\
\text { range and the range of the } \\
\text { observations. }\end{array}$ \\
\hline
\end{tabular}

806

Here, $f$ represents the 20 forecasted rainfall series, o represents the observed rainfall, $h$ is the number elements in the rainfall data series, and $\mathrm{F}$ indicates the ensemble range of 20 members 
823

824

825

826

827

828

829

Table 4. Monthly forecasting accuracy metric values for June rainfall in the UYRB and LYRB at 0 -, and 1-month lead time (the results for July, August, and September are presented in the Appendix A as Table S5)

\begin{tabular}{|c|c|c|c|c|c|c|}
\hline & & & MAI & & MRE (1 & \\
\hline UYRB-Jun & aw GCM & $\overline{\mathrm{LS}}$ & Raw GCM & $\overline{\mathrm{LS}}$ & Raw GCM & LS \\
\hline CFS & 0.11 & 0.04 & 48.3 & 14.7 & 36.2 & 11.4 \\
\hline MOM3-AC & 0.24 & 0.18 & 27.9 & 14.1 & 43.1 & 10.9 \\
\hline MOM3-DC & 0.34 & 0.28 & 57.6 & 12.9 & 42.9 & 10.2 \\
\hline CMC2 & 0.02 & 0.02 & 98.5 & 17.7 & 72.9 & 13.3 \\
\hline LYRB-June & & & & & & \\
\hline CFS & 0.17 & 0.11 & 30.9 & 32.5 & 14.8 & 16.6 \\
\hline MOM3-AC & 0.04 & -0.1 & 39.0 & 34.1 & 18.5 & 17.6 \\
\hline MOM3-DC & -0.1 & -0.1 & 41.0 & 33.1 & 19.7 & 17.3 \\
\hline $\mathrm{CMC} 2$ & 0.36 & 0.32 & 37.3 & 28.8 & 18.0 & 15.2 \\
\hline UYRB-June & & & & & & \\
\hline CFS & 0.23 & 0.1 & 39.2 & 10.6 & 29.6 & 7.9 \\
\hline MOM3-AC & -0.2 & -0.3 & 56.0 & 12.0 & 42.0 & $\overline{9.0}$ \\
\hline MOM3-DC & -0.3 & -0.3 & 56.4 & 12.9 & 42.3 & 9.7 \\
\hline $\mathrm{CMC} 2$ & 0.28 & 0.24 & 106.6 & 11.1 & 78.6 & 8.2 \\
\hline LYRB-June & & & & & & \\
\hline CFS & 0.08 & -0.1 & 42.9 & 31.2 & 20.1 & 16.4 \\
\hline MOM3-AC & 0.14 & 0.08 & 42.2 & 32.6 & 20.2 & 17.2 \\
\hline MOM3-DC & 0.17 & 0.11 & 42.9 & 33.6 & 20.2 & 17.7 \\
\hline $\mathrm{CMC} 2$ & 0.36 & 0.29 & 37.4 & 27.5 & 17.2 & 14.1 \\
\hline
\end{tabular}

830

831

832

833

834

835

The red italic underline indicates the best value of each metric.

Table 5. Seasonal forecasting metric values for JJA rainfall in the UYRB and LYRB at 0-month and 1-month lead times (the corresponding results for JAS rainfall are presented in Appendix A as Table S7)

\begin{tabular}{|c|c|c|c|c|c|c|}
\hline & \multicolumn{2}{|c|}{$\rho$} & \multicolumn{2}{|c|}{ MAE(mm) } & \multicolumn{2}{|c|}{ MRE $(100 \%)$} \\
\hline & $\overline{\mathrm{aw} \text { GCM }}$ & LS & Raw GCM & LS & Raw GCM & $\overline{\mathrm{LS}}$ \\
\hline \multicolumn{7}{|c|}{ UYRB-JJA lead 0} \\
\hline $\begin{array}{c}\text { CFS } \\
\text { MOM3-AC }\end{array}$ & $\frac{0.47}{0.08}$ & $\begin{array}{l}0.41 \\
-0.1\end{array}$ & $\begin{array}{l}22.4 \\
30.8\end{array}$ & $\begin{array}{r}9.9 \\
11.9\end{array}$ & $\begin{array}{l}16.2 \\
22.0\end{array}$ & $\frac{7.1}{8.3}$ \\
\hline MOM3-DC & 0.22 & 0.07 & 28.8 & 11.5 & 20.5 & 8.0 \\
\hline CMC2 & 0.03 & -0.1 & 47.0 & 15.2 & 33.1 & 10.6 \\
\hline \multicolumn{7}{|c|}{ UYRB-JJA lead 1} \\
\hline CFS & 0.06 & -0.1 & 19.9 & 11.9 & 14.3 & 8.3 \\
\hline MOM3-AC & 0.01 & -0.1 & 30.4 & 12.0 & 21.7 & 8.5 \\
\hline MOM3-DC & 0.15 & 0.01 & 27.4 & $\underline{11.2}$ & 19.5 & 7.8 \\
\hline CMC2 & $\underline{0.20}$ & 0.13 & 11.3 & 12.0 & 8.1 & $\overline{8.5}$ \\
\hline \multicolumn{7}{|c|}{ LYRB-JJA lead 0} \\
\hline CFS & 0.26 & 0.20 & 25.7 & $\frac{16.8}{10.7}$ & 22.6 & 13.9 \\
\hline MOM3-AC & -0.3 & -0.4 & 26.4 & 19.7 & 23.7 & 16.4 \\
\hline MOM3-DC & -0.1 & -0.2 & 26.4 & 17.8 & 23.4 & 14.7 \\
\hline CMC2 & 0.13 & 0.06 & 2.8 & 17.0 & 21.3 & 14.3 \\
\hline \multicolumn{7}{|c|}{ LYRB-JJA lead 1} \\
\hline CFS & $\underline{0.22}$ & 0.14 & 17.9 & 16.6 & 16.1 & 13.8 \\
\hline MOM3-AC & -0.1 & -0.2 & 22.4 & 18.8 & 20.1 & 15.7 \\
\hline MOM3-DC & -0.1 & -0.1 & 21.0 & 17.3 & 19.1 & 14.6 \\
\hline CMC2 & 0.10 & -0.1 & 21.9 & 16.6 & 19.5 & 13.8 \\
\hline
\end{tabular}


838

839

840

841

842

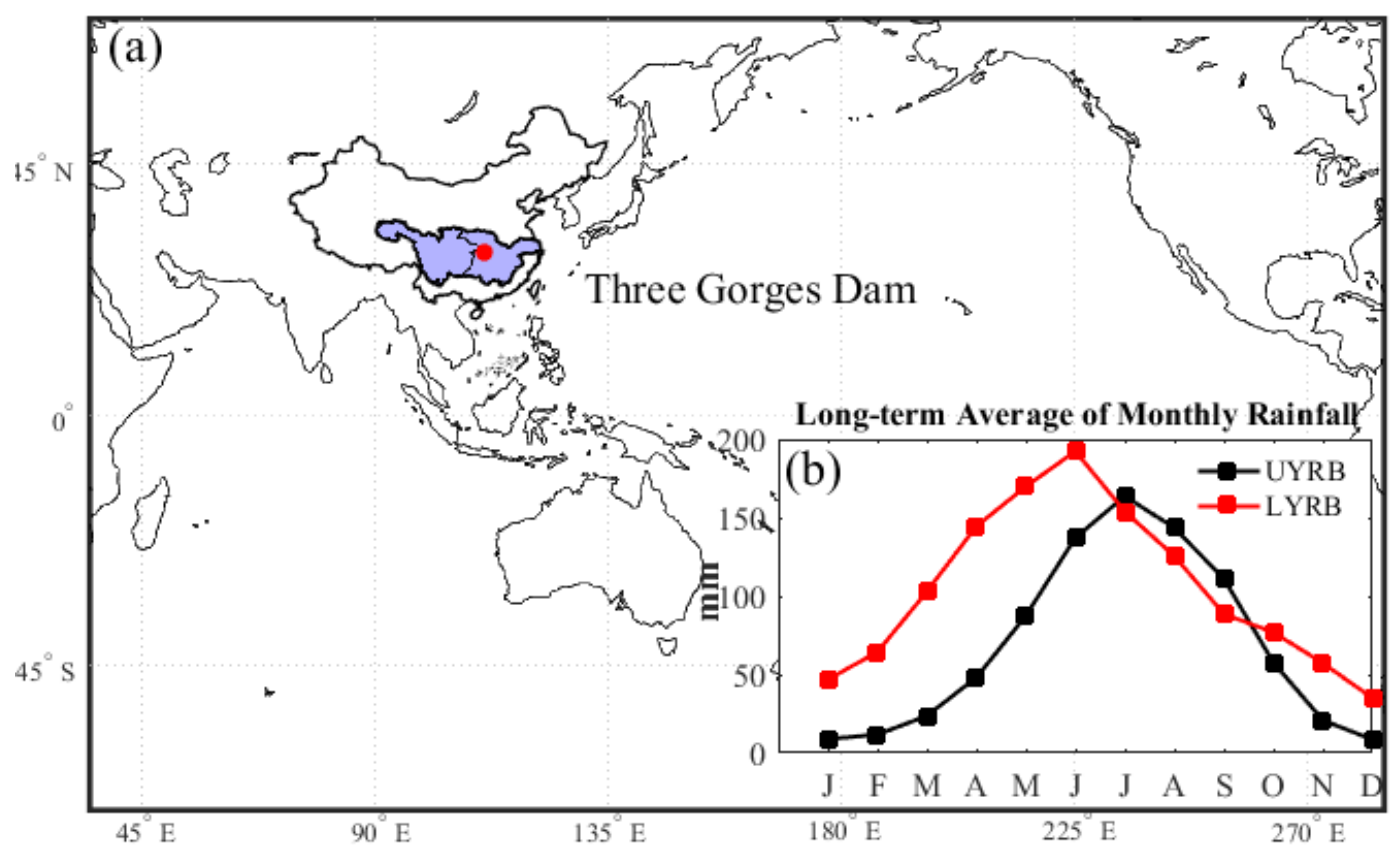

843

844

845

846

847

Fig. 1 (a) SSTA spatial domain and the locations of the upper and middle-lower sections of the Yangtze River basin with the Three Gorges Dam as the boundary (red dot). (b) Long-term average (1961-2010) of the monthly rainfall in UYRB and LYRB.
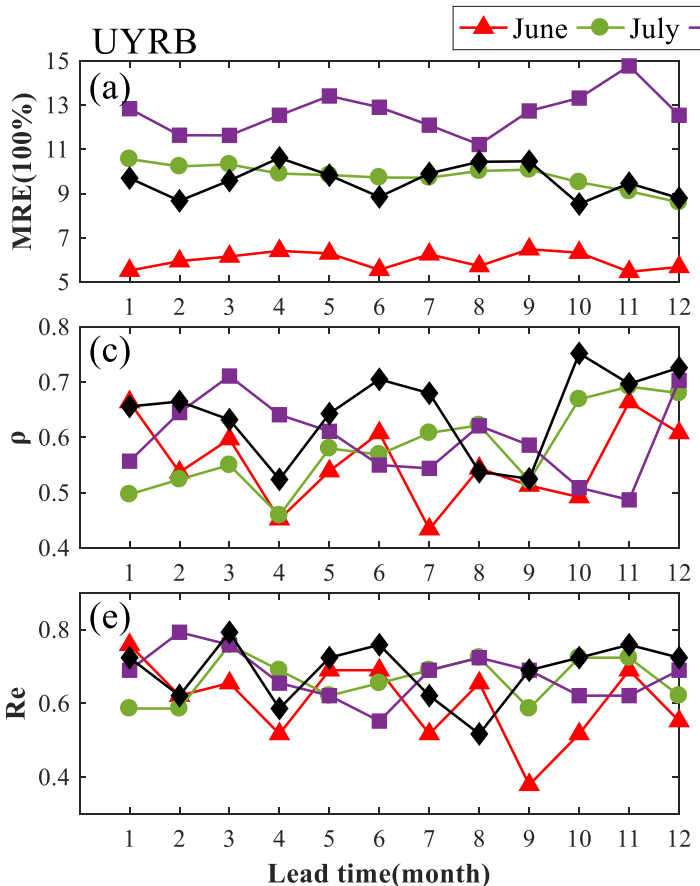
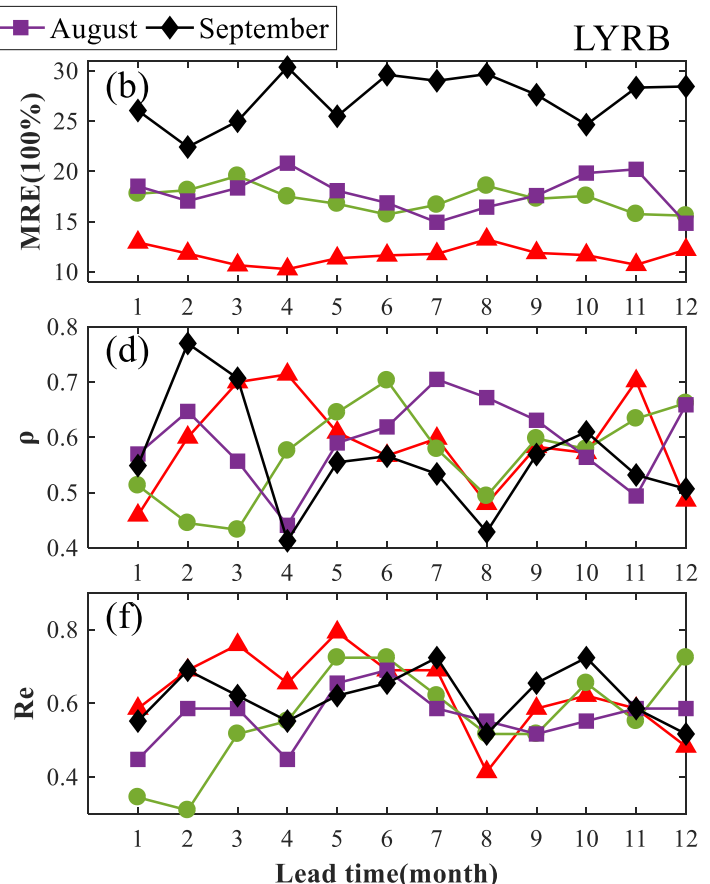
849

850

(a)

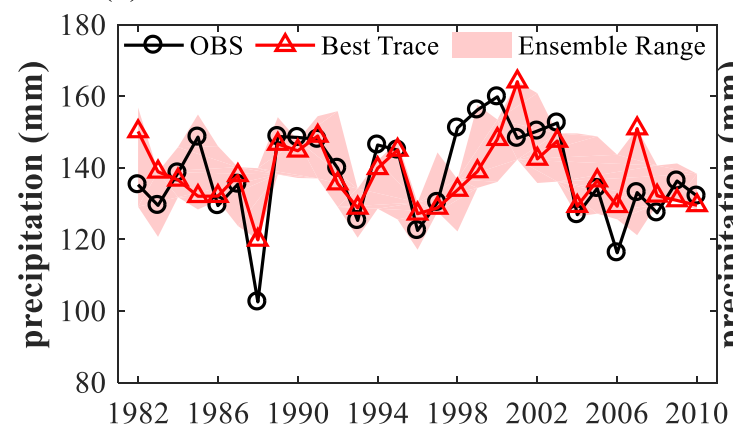

19821986199019941998200220062010 Year

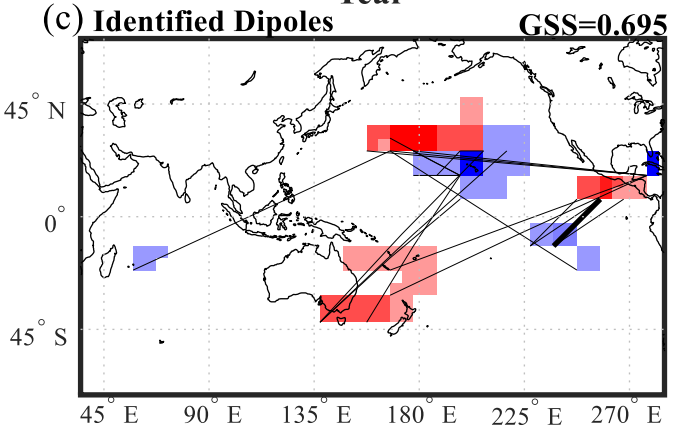

(b)

June:1-month Lead
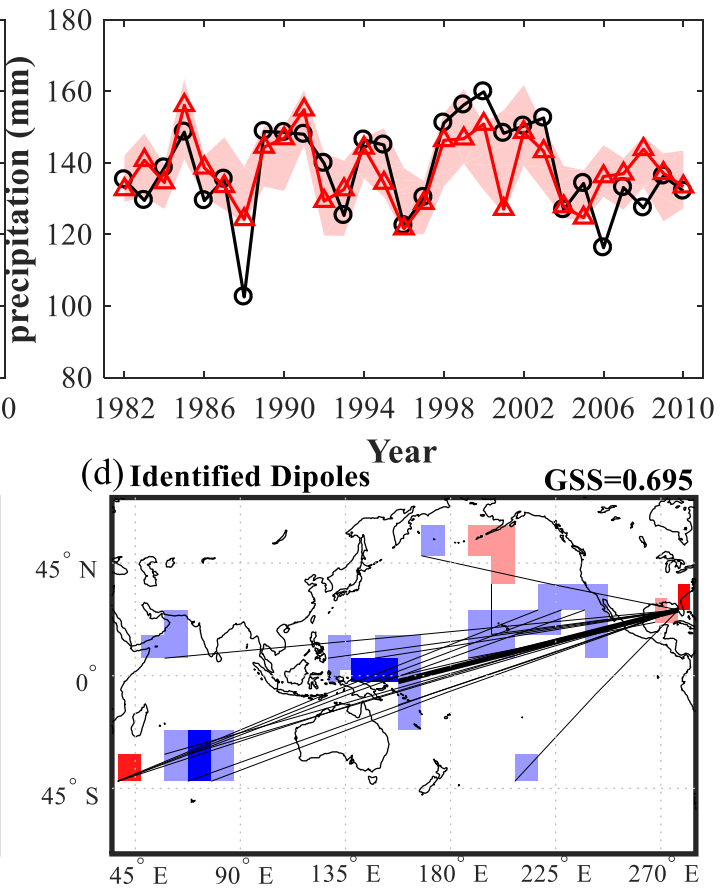

Fig. 3 Rainfall forecasting time series (Best Trace) and observed data (OBS) at two selected lead times and the corresponding dipoles for June in the UYRB. (a) and (c): 11-month lead; (b) and (d): 1-month lead. The light red shading in (a) and (c) represents the ensemble range based on the best 20 dipoles. The black lines in (b) and (d) are the best 20 dipoles formed between the positive poles given in red and negative poles given in blue (The best predicting dipoles are linked with the bold black line) 
(a)

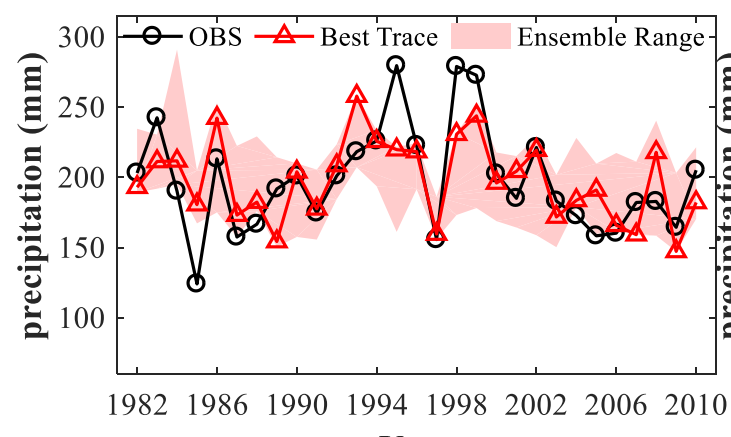

(c) Identified Dipoles Year

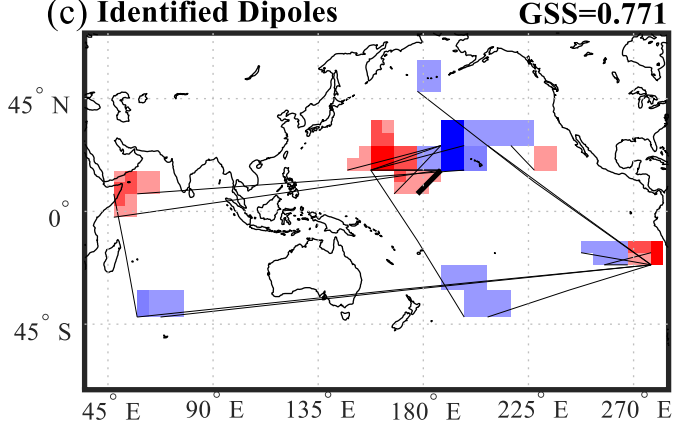

(b)

June:3-month Lead

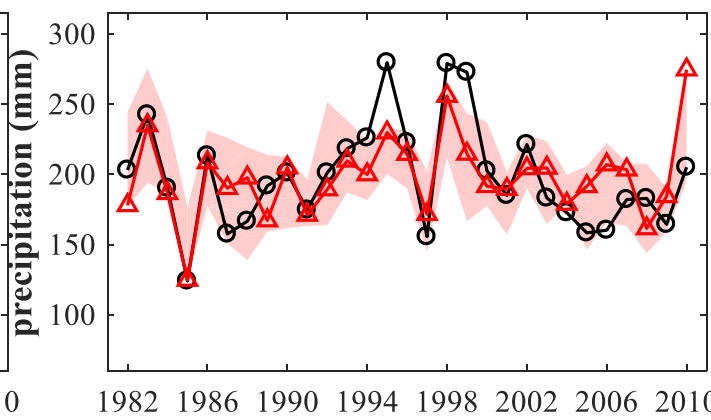

(d) Identified Dipoles Year

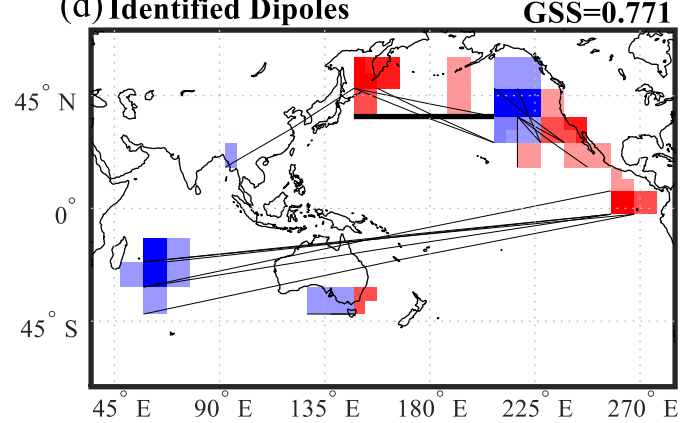

Fig. 4 As in Fig. 3, but for LYRB.
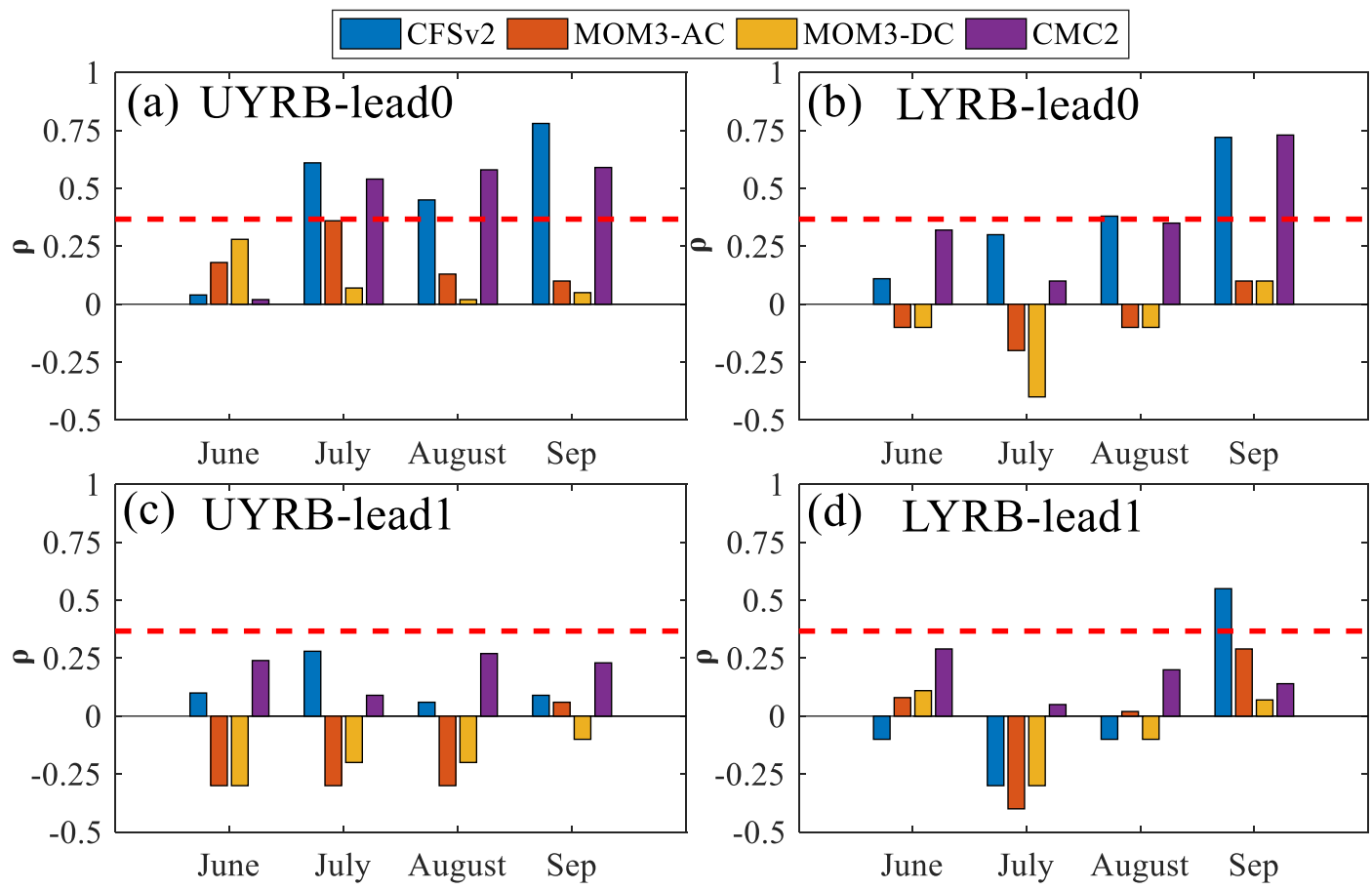

Fig. $5 \rho$ values after bias correction at 0 and 1 month lead times for four GCMs in the UYRB and LYRB. Values above the red dashed lines are significantly different from zero at a $5 \%$ level. 


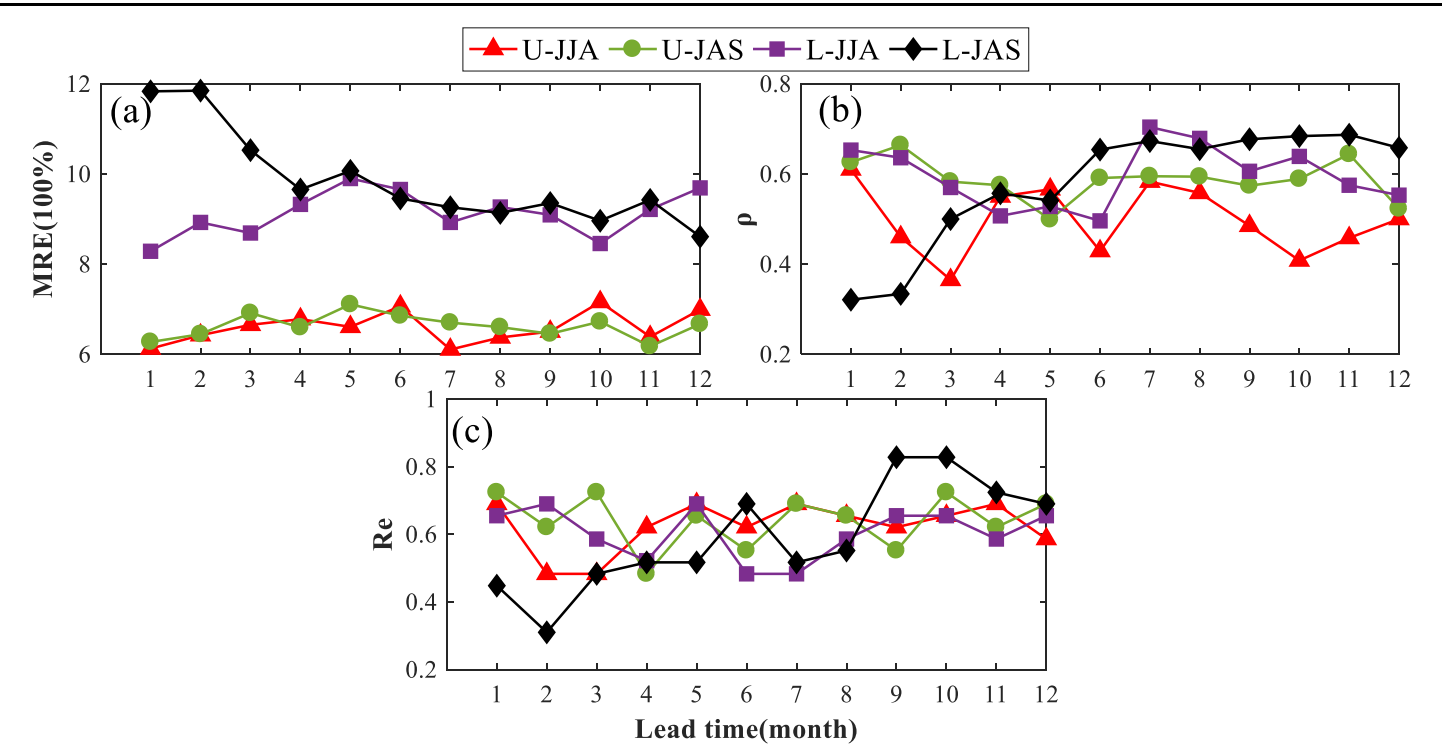

Fig.6 MER, $\rho$, and Re values of JJA, JAS rainfall for lead times of 1 to 12 months. U-JJA, U-JAS represent the JJA and JAS rainfall in UYRB, and L-JJA, L-JAS represent the JJA and JAS rainfall in LYRB.

(a)

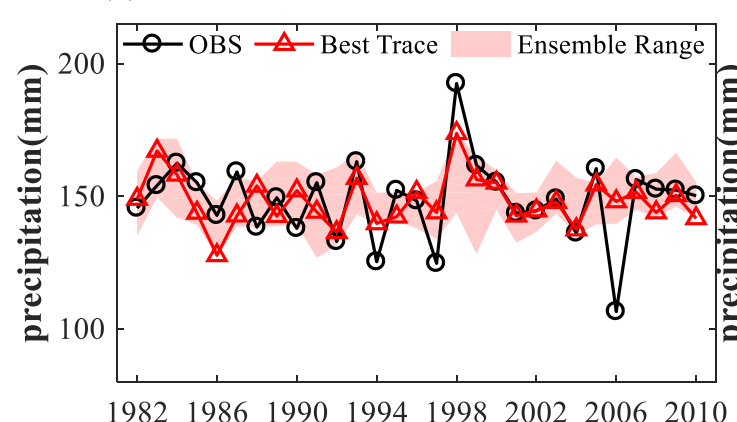

19821986199019941998200220062010

(c) Identified Dipoles Year

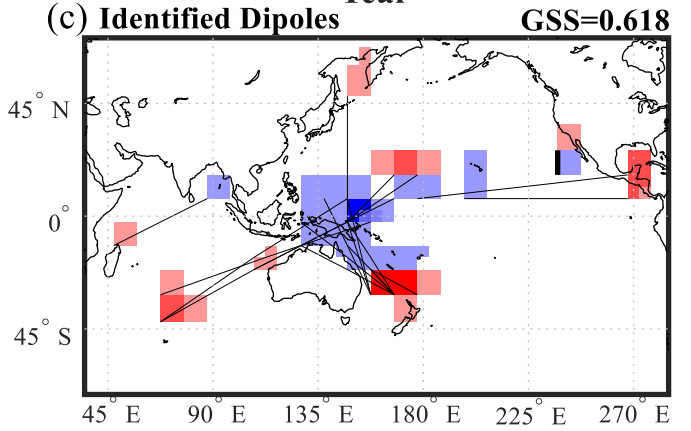

(b)

JJA:7-month Lead

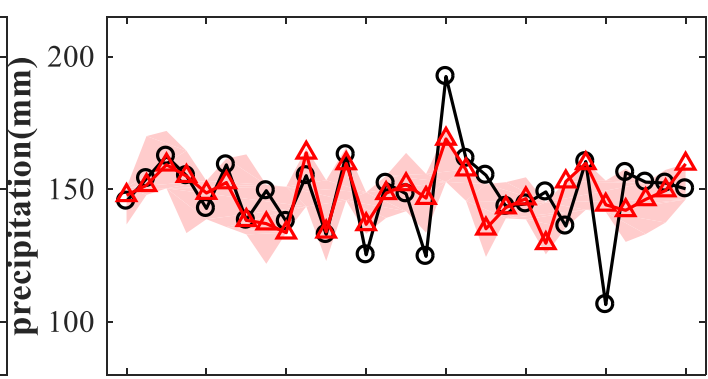

19821986199019941998200220062010

(d) Identified Dipoles Year

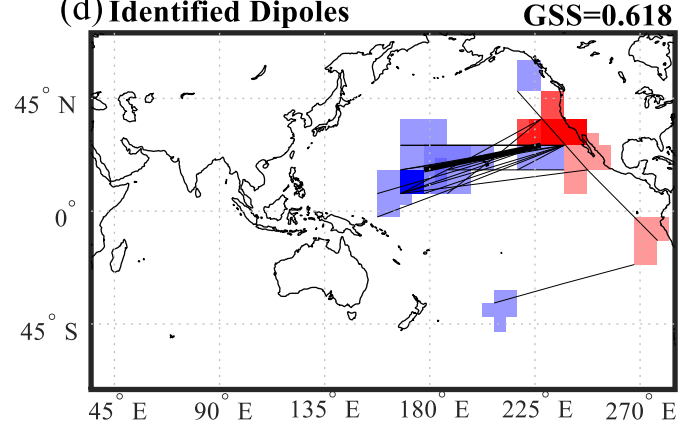

Fig. 7 Rainfall forecasting time series (Best Trace) and observed data (OBS) at two selected lead times and the corresponding dipoles for JJA in the UYRB. (a) and (c): 5-month lead; (b) and (d): 7month lead. The light red shading in (a) and (c) represents the ensemble range based on the best 20 dipoles. The black lines in (b) and (d) are the best 20 dipoles formed between the positive poles 
881 882

(a)

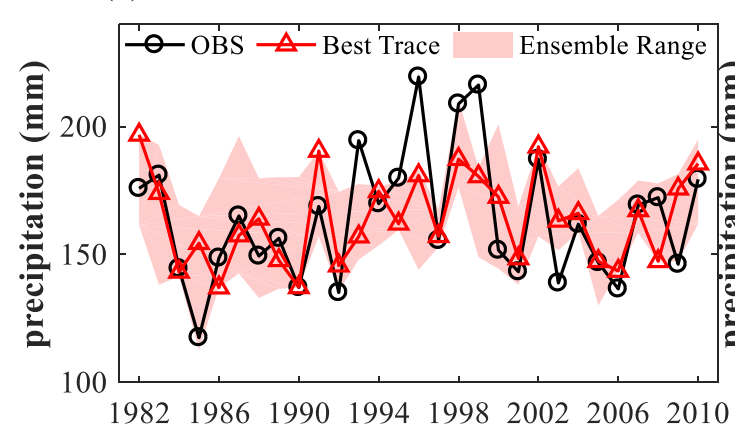

19821986199019941998
Year

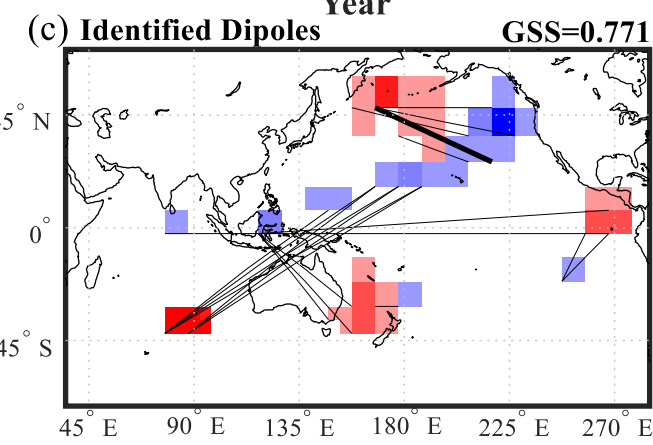

(b)

JJA:7-month Lead

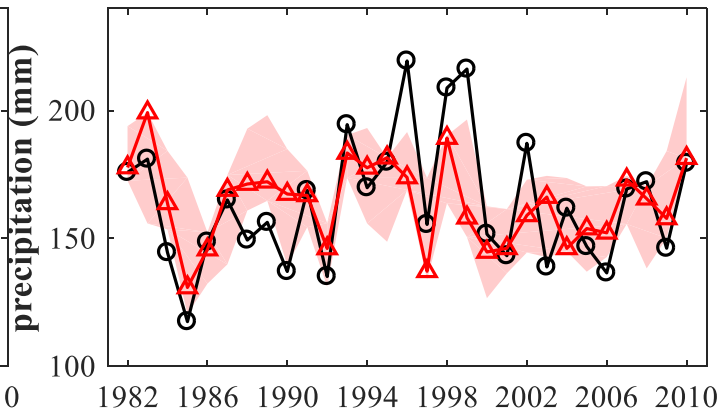

(d) Identified Dipoles Year

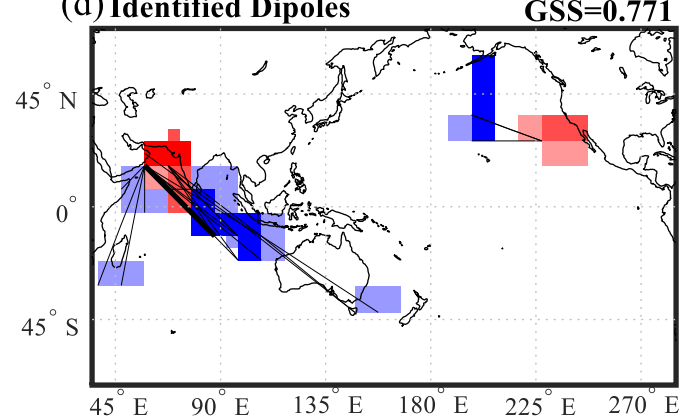

883

884

885

886

Fig.8 As in Fig. 7, but for LYRB.
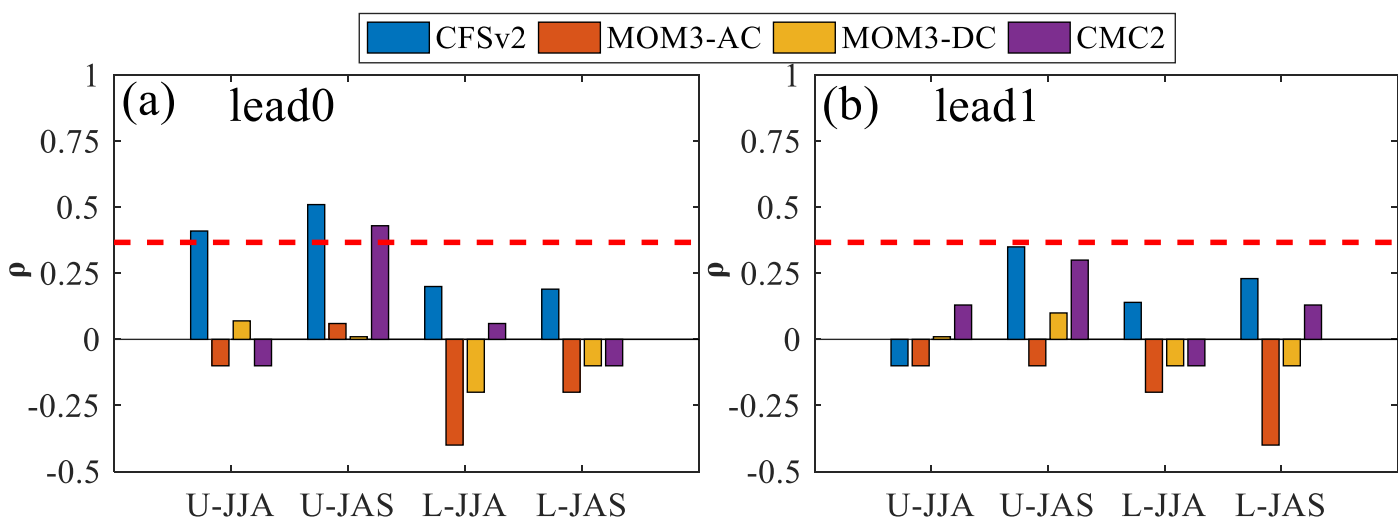

Fig.9 $\rho$ values after bias correction at 0 and 1 month lead times for four GCMs in the UYRB and LYRB. U-JJA, U-JAS represent the JJA and JAS rainfall in UYRB, and L-JJA, L-JAS represent the JJA and JAS rainfall in LYRB. Values above the red dashed lines are significantly different from zero at a $5 \%$ level. 
doi: 10.1002/joc.6216.

898

899

900 